\title{
SERVICE ROBOT ADOPTION AMONG EMPLOYEES: A CULTURAL PERSPECTIVE
}

\author{
N Alia Fahada W Ab Rahman'1, Monizaihasra Mohamed ${ }^{2}$ \& Farizah Sulong ${ }^{3}$ \\ 1,2,3Faculty of Business, Economics, and Social Development, Universiti Malaysia Terengganu \\ (n.alia@umt.edu,monizaihasra@umt.edu.my, farizah@umt.edu.my)
}

\begin{abstract}
This study examines the adoption of service robots by fast-food restaurant employees. Adopting the Unified Theory of Acceptance and Use of Technology (UTAUT), this study proposes four determinants of intention to use: performance expectancy (PE), effort expectancy (EE), social influence (SI) and facilitating conditions (FC). The role of culture was also considered to examine its role in moderating the influencing factors. The data was collected from Malaysian fast-food restaurant employees and analysed using the Statistical Package for Social Sciences (SPSS) and the Smart-PLS software. The findings showed that intention to use service robots is primarily influenced by performance expectancy and social influence. Additionally, culture also has a significant effect as moderating factor on the relationship between social influence and intention to use service robots in a fast-food restaurant setting. Lastly, a discussion on the contributions and implications are presented.
\end{abstract}

KEYWORDS: Service Robot, Employees' Acceptance, Fast-Food Restaurant, Culture, UTAUT

\section{PURPOSE AND BACKGROUND}

Robots are increasingly being adopted as service providers in the tourism and hospitality industries (FustéForné, 2021; Ivanov et al., 2019; Kuo et al., 2017; Murphy et al., 2017). Thus, many scholars argue that the real-world application of robotics in hospitality is booming across the world (Choi et al., 2020). In the restaurants for instance, robots are used to perform a wide range of tasks in the kitchen and even serving customers, working as replacements for chefs, waiters, baristas hostesses and servers (Hwang, 2020). Currently, robots are used in many western countries including the United States, Turkey and the United Kingdom and a few Asia Pacific countries such as China, Japan and South Korea (Hwang et al., 2020).

The adoption of service robots in Malaysia is still in its first phase. In 2018, Nam Heong restaurant became the first restaurant in Malaysia to use 8 robot waiters to serve and attend to customers (Says, 2018). Previous studies acknowledged that national cultures affected service cultures and influenced the way technology-mediated service may have manifest (Yu \& Ngan, 2019; Tuomi et al., 2020). Thus, culture appears as a cause to influence an individual to respond either positively or negatively to the use of service robots and it is important to use robots that can be easily accepted and integrated into the national culture.

This study was designed to examine the factors that influenced the adoption of service robots by fast-food restaurant employees. This study proposed that the four dimensions of the Unified Theory of Acceptance and Use of Technology (UTAUT) (i.e., performance expectancy, effort expectancy, social influence and facilitating conditions) have a positive influence on the overall robot adoption rates by restaurants and employees.

According to Venkatesh et al. (2003), performance expectancy refers to the degree to which an individual believes that using a technology will assist him or her achieve his or her job performance 
objectives; effort expectancy is defined as a measure of the ease correlated with the use of the system; social influence is defined as the extent to which individuals perceive the importance of others to believe they should use the new technologies while a facilitating condition is described as an individual's belief in the existence of an organisational and technological infrastructure capable of supporting the technologies.

This study also aims to understand the role of culture in the context of the adoption of service robots among employees. One of Hofstede's cultural dimensions that was incorporated in this study was uncertainty avoidance. Uncertainty avoidance refers to how threatened individuals are by ambiguity and also the perceived significance of norms and standards (Hofstede, 1991).

\section{METHODOLOGY}

This study employed a quantitative research approach to examine the relationship between performance expectancy, effort expectancy, social influence, facilitating conditions and the intention to use robots. This study also aims to understand the role of culture in moderating social influences and the intention to use robots.

The items for the UTAUT constructs were adapted from Venkatesh et al. (2003) and Venkatesh et al. (2012). For the moderating variable, the uncertainty avoidance constructs were adapted from Hofstede (1980). A total of 204 questionnaires were collected online. To obtain an adequate sample of the population, this study used convenience sampling. An email invitation was sent to the fast-food restaurant manager and upon receiving an approval, a link to the questionnaire was distributed to the employees via email and on the WhatsApp's mobile application. To achieve the objectives of the study, descriptive analysis and common method variance were analysed using SPSS version 26, while the measurement model and structural model were analysed using SmartPLS 3.0.

\section{FINDINGS}

It was found that performance expectancy ( $\mathrm{t}$-values $=2.110, \mathrm{p}<0.05)$ and social influence $(\mathrm{t}-\mathrm{value}=5.445$, $\mathrm{Cl}$ : $0.280,0.606)$ positively influenced the intention to use service robots among fast-food restaurant employees. With regard to the second research question, culture moderates the relationship between social influence and the intention to use robots. The findings show a significant negative effect of uncertainty avoidance on the relationship between social influence and the intention to use service robots. It implies that the negative relationship between social influence and the intention to use service robots would be stronger when uncertainty avoidance is lower. This is consistent with previous studies (Bankole \& Bankole, 2017).

\section{CONCLUSION}

The potential for the use of service robots in Malaysia is vast. This study shows that fast-food restaurant employees in the country have a higher tendency to adopt service robots if they realise that the service robots are useful in assisting them with their tasks. Also, if more influential people think that adopting service robots at fast-food restaurants is useful, it is more likely that employees will adopt the use of service robots in the restaurant. Employees also see it as challenging to work with service robots and the intention to use service robots is not influenced by the infrastructure at the restaurants or by their knowledge of the new technology. By integrating a cultural moderator, this study adds a stronger basis to predict the intention to use a service robot and thus provides more analytical potential to the existing UTAUT. 
This study could offer several significant recommendations to the service sector in Malaysia and also hopes that they could gain some benefits from this study by considering UTAUT and culture in practice. Research on various cultural settings and various cultural dimensions should be considered to provide a better understanding of robotic adoption by workers globally.

\section{CONTRIBUTION/PRACTICAL IMPLICATIONS}

Theoretically, this study postulates a foundation for additional improvement of individual models of acceptance. It implies that acceptance and cultural dimensions are suitable bases when examining cultural diversity in technology-based settings. From a managerial standpoint, understanding the key factors is important to develop, enhance and execute the adoption of service robots in fast-food restaurants to achieve high levels of employee acceptance. By understanding the main factors affecting employees' acceptance and constraints, fast-food restaurants in Malaysia will be able to cope with the rising customer demands and technological advancement to enhance the acceptance and support of the service robot adoption.

As, service robot adoption rates in restaurants and other service sectors are already being sensationalised and is already a success story in western countries and in some Asian countries, Malaysia should learn from the good examples already in place and benefit from new levels of acceptance and technology advancement.

\section{ACKNOWLEDGEMENTS}

Universiti Malaysia Terengganu supports this work under the research grant entitled Talent and Publication Enhancement -Research Grant (TAPE-RG55281).

\section{REFERENCES}

Hofstede, G., Hofstede, G. J., \& Minkov, M. (1991). Cultures and organizations: Intercultural cooperation and its importance for survival. Software of the Mind. London: McGraw-Hill.

Ivanov, S. H., Gretzel, U., Berezina, K., Sigala, M., \& Webster, C. (2019). Progress on robotics in hospitality and tourism: a review of the literature. Journal of Hospitality and Tourism Technology, 10(4), 489-521.

Venkatesh, V., Morris, M. G., Davis, G. B., \& Davis, F. D. (2003). User acceptance of information technology: Toward a unified view. MIS Quarterly, 425-478. 